\title{
Strategies to cope with stress among online gamers: A study among university students in Medan, Indonesia
}

\author{
Strategi-strategi mengatasi stres pada gamer online: Sebuah studi pada \\ mahasiswa-mahasiswi di kota Medan, Indonesia
}

\author{
Lusi Juliana Manalu' ${ }^{1}$, Indri Kemala*1 \\ ${ }^{1}$ Universitas Sumatera Utara, Kota medan, Indonesia
}

\begin{abstract}
The present study examines strategies of coping with stress among active online gamers in Medan, Indonesia. The study involved 400 students that could be classified as disordered gamers. The results show that the majority of participants tended to use a less useful coping strategy (36 percent), about 30 percent used an emotion-focused coping strategy, about 28 percent used a problem-focused strategy, and about 5 percent used other strategies that could not be classified.

Keywords: coping stress strategies, online game addiction, college students

Abstrak. Studi ini mengkaji strategi mengatasi stres di kalangan gamer online aktif di Medan, Indonesia. Penelitian ini melibatkan 400 mahasiswa-mahasiswi yang dapat digolongkan sebagai disordered gamers. Hasilnya menunjukkan bahwa mayoritas partisipan cenderung menggunakan strategi less useful coping (36 persen), sekitar 30 persen menggunakan strategi emotion-focused coping, sekitar 28 persen menggunakan strategi problem-focused, dan sekitar 5 persen menggunakan strategi lain yang tidak dapat diklasifikasikan.
\end{abstract}

Kata Kunci: strategi mengatasi stres, kecanduan online game, mahasiswa

\section{Pendahuluan}

Internet adalah salah satu jasa yang dapat memberikan informasi terbaru yang mendukung perkuliahan mahasiswa tersebut. Informasi yang disajikan ilmu pengetahuan, gaya hidup, dan banyak hal lain yang sedang tren di dunia. online game adalah salah satu konten hiburan yang paling sering dikunjungi di Indonesia (APJII, 2018). Hal ini patut menjadi perhatian karena dapat menimbulkan banyak dampak negatif terhadap individu pemain online game. Misalnya, ketika kalah dalam online game individu sering sekali menjadi cepat marah, emosional, dan berperilaku agresif (misal, memukul meja warung internet, berteriak keras) yang menimbulkan keresahan pada orang lain di sekitarnya (Anggraini, 2016). Tindakan-tindakan seperti yang telah disebutkan, merupakan gejala internet gaming disorder (selanjutnya akan disebut sebagai kecanduan online game), yaitu penggunaan internet yang terus-menerus dan berulang yang berakibat pada penurunan fungsi sehari-hari individu.

Di dalam penelitian ini, kami berusaha mendeskripsikan strategi mengatasi stres pada mahasiswamahasiswi pecandu online game. Hal ini penting untuk ditelaah mengingat bahwa simtom-simtom pecandu online game yang dijelaskan di DSM V tampak sangat relevan dengan pola mengatasi stres (akan dijelaskan lebih lanjut). Pengetahuan tentang pola strategi mengatasi stres pada pecandu

*Korespondensi: Jl. Dr. Mansyur 7, Kampus USU Padang Bulan, Medan, Indonesia

Surel: indri.kemala.nst@usu.ac.id 
online game ini dapat menjadi dasar bagi pihak-pihak terkait (misal, orangtua, kampus, terapis) untuk mendesain program penanggulangan kecanduan online game.

\subsection{Kecanduan game online}

Kecanduan online game dapat disebabkan oleh kurangnya perhatian orang-orang terdekat, depresi, kurang kontrol, kurangnya kegiatan, lingkungan sosial (misal pertemanan), dan pola asuh orangtua (Masya dan Candra, 2016). Seseorang yang mengalami kecanduan online game dapat menghabiskan 8-10 jam atau lebih perharinya untuk bermain online game (American Psychological Association, 2013). Mereka sangat fokus pada reward yang didapatkan dari online game ketika mereka mampu menghadapi setiap tantangan yang diberikan di setiap levelnya. Hal ini membuat peran para pecandu game online di dunia nyata terbengkalai yang akhirnya menimbulkan berbagai masalah dalam kehidupannya. Misalnya, rusaknya hubungan sosial dengan orang-orang di dalam kehidupan nyata, mengganggu aktivitas kehidupan sehari-hari (seperti, gangguan tidur, pekerjaan, dan pendidikan: American Psychological Association, 2013).

Simtom-simtom kecanduan online game dijelaskan dengan lengkap di Diagnostic and Statistical Manual of Mental Disorders edisi ke-5 (American Psychological Association, 2013), sebagaimana akan dijelaskan sebagai berikut. Seseorang dianggap kecanduan online game apabila mengalami lima atau lebih simtom selama 12 bulan. Beberapa simtom yang dimaksud adalah: (1) Memikirkan dan terpreokupasi dengan online game secara terus-menerus, (2) Merasa tidak enak hati apabila tidak dapat bermain online game, (3) merasa penting untuk terus-menerus menghabiskan waktu bermain game online, (4) tidak mampu berhenti dari game online, (5) kehilangan minat atas hal-hal yang sebelumnya disenangi, (6) memiliki masalah di pekerjaan, sekolah, atau rumah karena terus-menerus bermain game online, (7) terus bermain meskipun sudah banyak masalah-masalah yang terus menumpuk, (8) berbohong dengan orang-orang di sekitar tentang waktu yang dihabiskan bermain online game, dan (9) menggunakan online game sebagai sarana untuk meregulasi perasaan dan suasana hati.

Dari simtom-simtom tersebut di atas, dapat dikatakan bahwa seseorang yang mengalami kecanduan online game memiliki banyak permasalahan dalam hidupnya, hal ini tentunya menjadi sumber stres bagi sang pecandu. Lebih parah lagi, alih-alih berusaha mengatasi masalah-masalah yang ada, pecandu online game malah terus bermain sebagai sarana melarikan diri dari kenyataan. Sebagaimana akan dijelaskan berikutnya, mahasiswa-mahasiwi merupakan kelompok yang sangat rentan mengalami kecanduan online game. Mengingat bahwa mahasiswa-mahasiswai akan menjadi generasi penerus bangsa, strategi mengelola stres pada mahasiswa-mahasiswi pecandu online game menjadi hal yang sangat penting dilakukan.

\subsection{Mahasiswa-mahasiswi sebagai kelompok rentan}

Mahasiswa-mahasiswi pada tingkat Sarjana di Indonesia secara umum adalah remaja. American Psychological Association (2013) menyebutkan bahwa di Asia, remaja usia 12-20 tahun merupakan kelompok yang sangat rentan akan kecanduan online game. Senada dengan hal ini, survei yang dilakukan oleh Asosiasi Penyelenggara Jasa Internet Indonesia (APJII, 2018) menunjukkan bahwa rentang umur yang paling banyak menggunakan internet berada di rentang 15-24 tahun. Kebanyakan dari para pengguna remaja ini aktif bermain game online. Dengan kata lain, mahasiswa-mahasiswi pada tingkat Sarjana di Indonesia memiliki kerentanan untuk kecanduan online game. Oleh karena itu, 
bagaimana strategi mengatasi stres remaja, khususnya remaja yang terjerumus kecanduan online game menjadi penting untuk ditelaah. Baik itu sebagai dasar untuk memitigasi kecanduan online game atau sebagai dasar dalam merancang intervensi agar remaja tidak terjerumus ke dalam kecanduan online game.

Urgensi penelitian ini menjadi sangat penting terutama mempertimbangkan dampak yang dapat disebabkan oleh kecanduan game online terhadap prestasi akademik. Di dalam penelitiannya, Chandrasegaran (2016) menemukan bahwa 24 persen dari mahasiswa-mahasiswi yang menjadi partisipan penelitiannya, yang masuk kategori pecandu online game, memiliki prestasi akademik yang kurang memuaskan dibandingkan dengan mahasiswa-mahasiswi yang tidak masuk klasifikasi pecandu online game.

\subsection{Strategi-strategi mengatasi stres}

Stres terjadi ketika individu merasa masalah yang ia hadapi melebihi kemampuan yang ia miliki untuk mengatasi masalah yang sedang ia hadapi tersebut (Lazarus, dalam Lahey, 2012). Stres adalah respon individu terhadap stressor, yaitu keadaan-keadaan dan peristiwa-peristiwa yang mengancam individu (Santrock, 2015). Ketika merasa stres, individu perlu melakukan coping with stress, yaitu upaya mengelola dan mengatasi tuntutan-tuntututan yang ia nilai melebihi kapasitas dirinya (Lazarus dan Folkman, 1984). Setiap orang mengalami dan bereaksi terhadap stres dengan cara yang berbedabeda. Perbedaaan ini dapat terjadi karena reaksi seseorang terhadap stres dipengaruhi oleh banyak faktor, seperti pengalaman sebelumnya dengan stres, faktor perkembangan, prediktabilitas dan kontrol, dan dukungan sosial (Lahey, 2012).

Secara umum, ada dua strategi dalam mengatasi stres, yaitu problem-focused coping dan emotionfocused coping (Lazarus dan Folkman, 1984). Dalam problem-focused coping, individu mengatasi stres dengan cara mencari solusi konkrit atas permasalahan yang dihadapinya. Misalnya, seorang mahasiswa yang merasa statistik sebagai mata kuliah yang di luar kapasitasnya akan mencari jalan keluar dengan mengambil kursus khusus agar ia dapat mengatasi mata kuliah statistik sebagai sumber stresnya. Sedangkan emotion-focused coping adalah strategi mengatasi stres dengan mengendalikan respon emosional terhadap situasi yang menekan. Misalnya, sulit menggunakan problem-focused coping bagi individu yang ditinggal mati oleh orang yang dicintainya, di sini regulasi emosi dan perasaan, seperti penerimaan atas kepergian dan mengenang hal-hal positif selama bersama orang yang dicintai tesrebut menjadi strategi yang lebih adaptif. Selain dua strategi tersebut, strategi lainnya disebut sebagai less useful coping style, yaitu strategi pengelolaan stres yang sebetulnya tidak bermanfaat dalam mengatasi stres (Carver, Scheier, dan Weintraub, 1989).

\subsection{Strategi mengatasi stres pada pecandu online gaming}

Dalam satu penelitian, Schneider, King, dan Delfabbro (2018) menunjukkan bahwa remaja yang mengalami kecanduan online game kebanyakan melakukan denial (berperilaku seolah tidak ada masalah) dan melakukan behavioural disengagement (dengan sengaja tidak mau menghadapi masalah). Bahkan, sebagian partisipan penelitiannya menggunakan online game sebagai sarana mengatasi stres. Penelitian Schneider dan kawan-kawan ini menunjukkan bahwa ada kecenderungan pecandu game online untuk menggunakan strategi mengatasi stres yang disebut Carver et al. (1989) sebagai less useful coping style. Berdasarkan hal ini, kami tertarik untuk memetakan strategi-strategi mengatasi 
stres apa yang menjadi kencenderungan para mahasiswa-mahasiswi pecandu online game di kota Medan. Adapun kota Medan menjadi fokus penelitian karena fenomena kecanduan online game di kota ini mengkhawatirkan. Misalnya, Anggraini (2016) menunjukan, dari 98 orang remaja di kelurahan Asam Kumbang yang menunjukkan gejala kecanduan online game, 95 orang di antaranya memiliki kecenderungan perilaku agresif.

\section{Metode}

Secara umum, Penelitian ini menggunakan Metode Kuantitatif-Deskriptif. Partisapan kami minta untuk mengisi skala yang mengukur variabel penelitian yang digunakan. Berikut penjelasan metode penelitian ini.

\subsection{Partisipan}

Populasi dalam penelitian ini adalah mahasiswa kota Medan yang aktif bermain online game, yang berusia antara 17-21 tahun. Untuk mengukur tingkat kecanduan online game, setiap partisipan di dalam penelitian ini sebelumnya diberikan skala kecanduan online game. Jumlah sampel penelitian ini sebanyak 400 orang yang terdiri dari 241 orang laki-laki dan 159 orang perempuan berusia antara 17-21 tahun.

\subsection{Prosedur}

Peneliti mengumpulkan data dengan menggunakan incidental sampling. Peneliti meminta kesediaan dari partisipan dan memastikan apakah mereka sudah termasuk kategori partisipan yang dibutuhkan. Kemudian peneliti memberikan booklet yang berisi informed consent dan skala kecanduan online game dan skala strategi coping stress.

\subsection{Alat ukur}

Semua skala kami buat dalam format skala empat titik. Strategi pengelolaan stres kami buat dengan mengacu pada penjelasan Carver et al. (1989), yang dibuat dalam format jawaban empat titik ( 1 = sangat tidak setuju- 4 = sangat setuju; $\alpha=.89$ ). Untuk mematikan bahwa semua partisipan benar dapat diklasifikasikan sebagai pecandu online game, kami menggunakan versi adaptasi dari alat ukur Lemmens, Valkenburg, dan Gentile (2015) yang diadaptasi oleh Mursyad, Karmiyati, dan Hidayati (2019) yang sebagian aitem telah kami modifikasi. Alat ukur ini dibuat dalam format skala Guttman dan telah dipastikan reliabilitasnya $(\alpha=.94)$.

\section{Hasil}

Penelitian ini adalah penelitian yang bertujuan untuk menggambarkan variabel penelitian sehingga peneliti menggunakan teknik analisa deskripsi. Sebelum mendapat hasil deskripsi variabel pada responden, peneliti melakukan kategorisasi terhadap skor responden pada setiap variabel. Kategorisasi untuk variabel strategi coping stress yang terdiri dari problem focused coping, emotion focused coping, dan less useful coping dilakukan dengan menggunakan teknik analisa skor Z. Sedangkan kategorisasi untuk variabel kecanduan online game dilakukan dengan menggunakan rumus kategorisasi 3 kelas, yaitu ringan, sedang, dan berat. Hasil penelitian ini menunjukkan bahwa tingkat kecanduan online game pada mahasiswa di kota Medan termasuk ke dalam kategori sedang. Hal tersebut disimpulkan 
Tabel 1: Gambaran Strategi coping stress online gamer

\begin{tabular}{lrrrrr}
\hline Kategori & Unclassified & $\begin{array}{r}\text { Problem } \\
\text { focused }\end{array}$ & $\begin{array}{r}\text { Emotion } \\
\text { focused }\end{array}$ & Less useful & Total \\
\hline Ringan & 7 & 35 & 44 & 39 & 125 \\
Sedang & 5 & 50 & 55 & 66 & 176 \\
Berat & 8 & 28 & 23 & 40 & 99 \\
Total & 20 & 113 & 122 & 145 & 400 \\
\hline
\end{tabular}

karena mayoritas responden atau sekitar 44 persen dari total.responden dalam penelitian ini berada pada kategori sedang. Kemudian 31 persen responden berada pada kategori ringan dan sisanya termasuk ke dalam kategori berat sekitar 24 persen.

Berdasarkan hasil penelitian ditemukan bahwa strategi coping stress yang paling banyak digunakan adalah less useful coping yaitu sebanyak 145 responden atau sekitar 36 persen dari total. Kemudian emotion-focused coping yang digunakan oleh 122 responden atau sekitar 30 persen dari total. Sedangkan problem-focused coping digunakan oleh 113 responden atau sekitar 28 persen dari total. Sementara itu terdapat 20 responden atau sekitar 5 persen dari total yang tidak memperlihatkan secara spesifik strategi coping stress yang mereka gunakan. Kemudian peneliti menganalisa gambaran strategi coping stress terhadap tingkat kecanduan online game yang dianalisa dengan teknik analisa crosstabs yang dapat dilihat pada Tabel 1 .

Dari Tabel 1 dapat dilihat bahwa mahasiswa yang kecanduan online game pada kategori ringan strategi coping stress yang paling banyak digunakan adalah emotion focused coping sebanyak 44 orang sedangkan pada mahasiswa yang kecanduan online game kategori sedang dan berat lebih banyak menggunakan less useful coping sebagai strategi coping stress mereka yaitu 66 orang pada kategori sedang dan 40 orang untuk kategori berat.

\section{Diskusi}

Berdasarkan penelitian yang telah dilakukan dapat disimpulkan bahwa gambaran strategi coping stress pada mahasiswa yang kecanduan online game di kota Medan menunjukkan bahwa less useful coping merupakan strategi coping yang cenderung lebih digunakan sesuai dengan hasil penelitian yang menunjukkan bahwa 145 gamers menggunakan less useful coping sebagai upaya untuk menghadapi masalah yang dialami. Sedangkan tingkat kecanduan online game pada mahasiswa di kota Medan berada pada tingkat kategori sedang.

Penelitian ini merupakan penelitian dasar yang hanya melihat gambaran strategi coping stress pada mahasiswa yang kecanduan online game di kota Medan. Pada penelitian selanjutnya, peneliti lain dapat mempertimbangkan untuk mencari tahu bagaimana hubungan ataupun pengaruh antara variabel kecanduan online game dan strategi coping stress pada mahasiswa di kota Medan. Peneliti juga menyarankan kepada peneliti selanjutnya yang ingin meneliti variabel kecanduan online game sebaiknya menyertakan jumlah nominal waktu yang sudah digunakan responden dalam bermain online game sehingga peneliti bisa melihat dampak terhadap strategi coping stress yang dialami responden kecanduan online game berdasarkan waktu yang sudah mereka gunakan untuk bermain online game.

Hasil penelitian ini dapat digunakan sebagai referensi untuk melihat gambaran strategi coping 
stress pada mahasiswa yang kecanduan online game di kota Medan yang mana kebanyakan menggunakan less useful coping yang bisa saja menambah masalah baginya dan membuatnya menjadi semakin stres. Dengan penelitian ini, peneliti berharap agar mahasiswa bisa memilih dan menggunakan strategi coping stress yang lebih efektif untuk menyelesaikan permasalahannya tanpa menimbulkan masalah baru.

Melalui penelitian ini, orangtua mahasiswa dapat memahami stres yang dialami anaknya yang kecanduan online game sehingga bisa berperan aktif untuk membantu anaknya menangani stres yang dialami. Orang tua dapat menjadi role model atau melakukan sharing tentang pengalaman ia mengalami stres ketika kuliah dan menghadapi stres tersebut. Bagi para dosen dapat mengetahui sumber stres yang dialami oleh para mahasiswa, sehingga para dosen dapar menggunakan metode pengajaran yang tepat dan menentukan beban tugas yang dapat dikerjakan mahasiswa dengan baik.

Dari penelitian ini peneliti menyimpulkan bahwa online game bisa memberikan dampak positif sekaligus dampak negatif bagi penggunanya. Dengan demikian perlu diberlakukan aturan dan pengawasan pada pengguna online game, khususnya kelompok usia remaja. Remaja merupakan kelompok usia yang memiliki kemungkinan paling tinggi mengalami kecanduan online game. Peneliti berharap pengguna online game bisa memanfaatkan dampak positif yang diberikan dan tetap terkontrol dalam penggunaannya sehingga tidak menimbulkan dampak negatif bagi dirinya.

\section{Referensi}

American Psychological Association. (2013). Diagnostic and statistical manual of mental disorders. London: American Psychiatric Publishing.

Anggraini, Y. (2016). Dampak penggunaan game online terhadap perilaku remaja.

APJII. (2018). Laporan asosiasi penyelenggara jasa internet Indonesia. Jakarta.

Carver, C. S., Scheier, M. F., dan Weintraub, J. K. (1989). Assessing coping strategies: A theoretically based approach. Journal of Personality and Social Psychology, 56, 267-283. https://doi.org/10.1 037/0022-3514.56.2.267

Chandrasegaran, S. (2016). Hubungan kecanduan online game dengan indeks prestasi akademik pada mahasiswa fakultas kedokteran universitas sumatera utara angkatan 2012.

Lahey, B. (2012). Psychology: An introduction (11th ed.). New York: The McGraw Hill Companies, Inc.

Lazarus, R. S., dan Folkman, S. (1984). Stress, appraisal, and coping. New York: Springer Publishing Company.

Lemmens, J. S., Valkenburg, P. M., dan Gentile, D. A. (2015). The Internet Gaming Disorder Scale. Psychological Assessment, 27, 567-582. https://doi.org/10.1037/pas0000062

Masya, H., dan Candra, D. A. (2016). Faktor-faktor yang mempengaruhi perilaku gangguan kecanduan game online pada peserta didik kelas X di Madrasah Aliyah Al Furqon Prabumulih tahun pelajaran 2015/2016. Konseli: Jurnal Bimbingan Dan Konseling, 3, 103-118.

Mursyad, A. G., Karmiyati, D., dan Hidayati, D. S. (2019). Pengaruh kesepian terhadap kecenderungan internet gaming disorder pada pemain battle royale game cognicia. 7, 228-240.

Santrock, J. W. (2015). Life-span development. New York: McGraw-Hill Education.

Schneider, L. A., King, D. L., dan Delfabbro, P. H. (2018). Maladaptive Coping Styles in Adolescents with Internet Gaming Disorder Symptoms. International Journal of Mental Health and Addiction, 
16, 905-916. https://doi.org/10.1007/s11469-017-9756-9 